\title{
A CIRANDA DE TODOS NÓS
}

Renata Celina de Morais OTELO ${ }^{1}$; Marcílio de Souza VIEIRA ${ }^{\mathbf{2}}$

${ }^{1}$ Mestra em Artes Cênicas pela Universidade Federal do Rio Grande do Norte. E-mail: renatacelina@hotmail.com

${ }^{2}$ Professor da Universidade Federal do Rio Grande do Norte E-mail: marciliov26@hotmail.com

Artigo submetido em Maio/2016 e aceito em Julho/2016

\section{RESUMO}

Da Ciranda litorânea, vivenciada na Praia de Jaguaribe/PE, Lia de Itamaracá pulveriza suas canções e alimenta a tradição da Dança da Ciranda pelos estados brasileiros e no exterior. Seus brincantes se dão à dança e em circularidade, trocam e tocam suas vidas, sua energia, seus movimentos. A partir da fenomenologia merleau-pontiana, lançamos um olhar sobre este fenômeno dançante apresentando como objetivo fundante apresentar reflexões sobre os corpos brincantes da Ciranda, especificamente, de Lia de Itamaracá e como esse corpo dança, se comunica, se escreve no tempo e no espaço, estabelece relações que o complementam e o ajudam a permanecer em construção. Assumimos, portanto, uma concepção de corpo que se referencia na abordagem fenomenológica merleau-pontiana, assim como na sua criticidade em relação ao corpo como um ser fragmentado, tal qual aponta a teoria Cartesiana. Fomos, assim, conduzidos pelo método fenomenológico e, dele, utilizamos os conceitos de mundo vivido e sensível que dialogam com o pensamento do filósofo Merleau-Ponty. Interessa-nos, ainda, nessa manifestação, o corpo que dança e se insere na expressão artística, que significa e se abre ao conhecimento pela via da experiência. Nessa perspectiva, entendemos o corpo na sua relação com os fazeres culturais, sociais, econômicos e artísticos que integram sua formação.

PALAVRAS-CHAVE: Brincantes; Ciranda; Lia de Itamaracá

\section{ABSTRACT}

\section{THE CIRANDA OF ALL OF US}

From Ciranda litorânea (a typical dance in circle in Brazil), experienced in Jaguaribe Beach/PE, Lia de Itamaracá pulverizes his songs and feeds the tradition of dance Ciranda by Brazilian states and abroad. His players bodies to give dance and circularity, touch and touch their lives, their energy, their movements. From merleaupontyan phenomenology we launched a look at this dancing phenomenon has as main objective to present the refletions about the players bodies, specifically, of Lia de Itamaracá and with this body to dance, to communicate, to mark itself on time and space, estabilishing relations that complement and help to stay in construction. Therefore, we assume a conception of the body that refers itself in the merleaupontyan fenomenologic approach, in this way, in its criativity in relation to the body as a fragmented being, as it is pointed by the Cartesiana theor We are, like this, conducted by the phenomenological method and, from it, we use the concepts of lived and sensitive world that dialogue with the thought of the Philosofer Merleau Ponty. Our interest in this manifestation is, also, the body that dances and insert itself in the artistic expression, meaning and opening itself to the knowledge by the experience. In this perspective, we understand the body in its relations with the cultural, social, economic and artistics issues that integrates it, in others words, in the relations that helped us to better understand the body as it is.

Key words: Players bodies; Ciranda; Lia de Itamaracá 


\section{INTRODUÇÃO}

Esta escrita versa sobre a pesquisa dissertativa realizada sobre o fenômeno dançante da Ciranda de Lia de Itamaracá que parte das margens da Praia de Jaguaribe, Pernambuco e se dissipa pelo país e além.

Ao chegar, ouvir o barulho da água que lambe a areia por uma, duas e várias vezes, é que iniciamos o sentir da essência que tem esse canto do mundo. Não havia pele que resistisse ao toque das ondas e não se desse ao movimento nas rodas de Ciranda que apareciam em seus dias nas situações mais diversificadas. Da areia ao asfalto, a Ciranda de Lia de Itamaracá pulsava forte à beira da Praia de Jaguaribe, localizada na Ilha de Itamaracá no estado pernambucano, e tem percorrido os terreiros em várias partes do país, por onde acompanhamos durante os anos de pesquisa do fenômeno (2014-2016).

Neste período encontramos histórias relatadas na oralidade popular a respeito da Ciranda como sendo uma típica dança da região praieira, em que as mulheres se reuniam para esperar a volta dos seus maridos do mar com cantos e danças numa formação circular, geralmente à beira da praia ou ainda em praças da comunidade em que viviam.

Na literatura, é de longa data que registramos a formação em rodas; em D'Amorim e Araújo (2003), por exemplo, encontramos pesquisas sobre os povos egípcios que interpretavam a partir dos astros, o ritmo do universo que se dava no fluxo da roda, assim como dançavam em torno de um altar, que representaria o sol com o propósito de exemplificar o movimento dos dias e dos anos. Nesse estudo encontramos escritos ainda mais remotos a respeito das sociedades primitivas em que a dança em roda se realizava, como escreve D’Amorim e Araújo (2003), “[...] em volta de um símbolo de caráter mágico de um deus, de um animal sagrado, de um objeto representativo, em volta do qual um grupo se movimenta [...]" (D'AMORIM E ARAÚJO, 2003, p. 118), assim, configurando esta prática como um desenho coreográfico e estrutural presente em diversas civilizações, que atravessou o tempo e se perpetua na contemporaneidade com estudos de variadas naturezas, inclusive no campo educacional. A estrutura circular também se faz presente na dança da Ciranda.

Diríamos ainda que nas danças circulares de forma geral, a disposição dos participantes em círculo mantém a proximidade dos brincantes, o toque, o corpo e a energia do outro circula, observa e se permite observar, troca.

Este artigo introduz o leitor ao conceito e estrutura estética da Ciranda de Lia de Itamaracá, situa os brincantes com os quais se teve proximidade durante a pesquisa, tece as vivências e implicações do corpo cirandeiro da própria pesquisadora e suas percepções apresentadas a partir do corpo que se é, e que ao dispor sua corporeidade no fenômeno, se dá ao conhecimento do mundo sendo carne deste mundo.

A pesquisa teve como guia a vivência do método fenomenológico desenvolvido a partir do pensamento do filósofo Merleau Ponty (1999, 2004a). Deste método buscamos imergir no fenômeno a partir dos conceitos de mundo vivido e sensível do referido autor. Assim, é parte dessa construção colocar o fenômeno entre parênteses e trazer a mostra a partir da escrita, o que o corpo escreveu no espaço, ou seja, o que por ele foi conhecido. 
Dialogamos com o mundo vivido como referência primeira para reflexão, por isso estaremos considerando-o nesse registro, tendo em vista as experiências vivenciadas pelos brincantes da Ciranda, pela Cirandeira Lia de Itamaracá e pela própria pesquisadora, não se restringindo a somente analisar o fenômeno, mas a nossa inserção nele. Nesta direção comungamos com o pensamento de Martins (1992) quando reflete sobre o mundo vivido: o mundo-vida do pesquisador é aqui considerado, o que o permite interrogar o mundo e os fenômenos que deseja indagar.

Consistiu, nessa trajetória, ir às coisas que já existem e já foram vistas, só que agora na perspectiva do olhar daquele que o observa e vivencia, o que trás novas anotações por apresentar elementos do mundo-vida que agora o formula. Ou seja, é uma trajetória que passa pelos sentidos e pelo que Merleau-Ponty denomina de sensível, sendo este o ato de sentir, o campo da sensibilidade na qual não se está para explicar o ocorrido, mas descrever a experiência vivenciada. É o espaço das sensações em que sinto e por ele, no outro, sou sentido; é colocar o corpo em sensibilidade para se dar a conhecer.

Bem vindos a este balanço: Vamos dançar Ciranda!

\section{CÍRCULO E AS MÃOS}

Em espaços e festejos múltiplos como praças, avenidas, bares e carnavais as Cirandas em Pernambuco tem espaço garantido quando se trata de festejar. Ultrapassando seu significado primeiro de brincadeira infantil, a Ciranda consegue abarcar diferentes grupos que se aproximam da roda dançante e, incorporando-se no tecer de suas nuances, entram e se tornam parte desta dança.

Encontramos também em países como a Irlanda, País de Gales, Inglaterra, Escócia, dentre outros, vivências dançantes que possuem a mesma estrutura da nossa Ciranda, o que leva pesquisadores, como Elvira D’Amorim e Dinalva Araújo (2003) a ampliar o discurso de suas influências e origem, trazendo possibilidades que vão além das apontadas pela oralidade, como praieiras. Nesta escrita nos respaldamos em autores como Sônia Teller (2009) e Cascudo (2001) ao dizer que a Ciranda é uma dança de roda popular na cultura brasileira, mas em Pernambuco ela assumiu um caráter particular por se apresentar como dança de roda de adultos, ritmada pela batida da percussão, com instrumentos como ganzá e tarol.

Em sua estética é possível verificar que os dançadores movimentam-se de mãos dadas e balançam o corpo numa movimentação circular que envolve deslocamento no ritmo lento e repetitivo das canções. Dança-se agarrado pelas mãos, pelos dedos, braço com braço, totalmente estendidos ou encolhidos num jogo de corpo para frente e para trás, com braços que se elevam para o alto e para baixo, sendo ainda possível verificar variações que ocorrem conforme a roda vai acontecendo e os brincantes vão se envolvendo na dança.

Dançada por homens, mulheres, meninas e meninos é conceituada como dança democrática por englobar todo brincante interessado. A aparente simplicidade e a uniformização são elementos possíveis de se identificar na Ciranda cuja mestra, Lia de Itamaracá, dá ritmo ao compasso animando seus participantes sendo a voz regente dessa brincadeira, desse coro, que se nivela aos brincantes, sendo também estes chamados de 
Cirandeiros. Isso nos faz compreender que a homogeneidade da roda assume um sentido maior, passando pela movimentação em círculo - desenho coreográfico - e se ampliando na denominação dos seus próprios participantes, ou seja, a mestra é denominada Cirandeira e os brincantes, Cirandeiros.

Entendemos que essas nomenclaturas acentuam ainda mais o nivelamento da dança que traz círculo como base numa estrutura que não reconhece o primeiro, nem o último, mas que todos se dão a ver de modo igual. Nessa roda estão convidados a bailar os corpos que se sentirem disponíveis a entrar e se dar à dança. Com começos e fins determinados pelo seu próprio corpo, é o brincante que em seu tempo entra ou sai do círculo sem que haja acordos formalizados.

A Ciranda de Lia de Itamaracá aparece na cena contemporânea dentro do universo dos saberes e danças tradicionais, como organismo vivo e pulsante, que se integra no fazer artístico-cultural, sendo revisitada e ressignificada a cada nova roda, a cada novo brincante que entra ou sai da movimentação, que experiencia no corpo e atribui significado ao que por ele é dançado. Não se tratando de uma única roda de Ciranda, mas de uma nova roda composta pelo público de cada apresentação da Cirandeira, percebemos que a movimentação é reinventada e está aberta a novas configurações constantemente, mantendo sua base do círculo que é uma das marcas desta dança.

A Cirandeira tem transpassado as barreiras geográficas com apresentações artísticas frequentes nas cinco regiões do Brasil, mantendo um fluxo permanente de apresentações em sua agenda em cidades como Rio de Janeiro, São Paulo e Brasília, por exemplo, e alcançando proporções de distâncias ainda maiores com shows no exterior em turnês na França, Estados Unidos e Alemanha. A Ciranda é cada vez mais de todos nós.

\section{O CORPO BRINCANTE}

Nessa conjuntura, cumpre frisar que falar dos brincantes da Ciranda é considerar as dimensões, os espaços e a multiplicidade dos brincantes nativos da llha de Itamaracá, dos turistas que frequentam as rodas na llha de Itamaracá, dos diversos públicos de suas apresentações em praças e teatros do Brasil e exterior, da própria Cirandeira e do meu próprio corpo durante os anos de pesquisa vivenciando este fenômeno.

Entendemos que elementos como o espaço que está sempre a se modificar, o figurino, a musicalidade e a mudança na movimentação dos brincantes de cada nova roda, são alguns fatores que acionam uma permanente reconfiguração que vem acontecendo na dança da Ciranda atualmente.

No que tange as reflexões a respeito da importância do treinamento corporal e da disciplina do corpo para a execução da dança, conforme nos apresenta a professora Inaicyra Falcão (2006) nos estudos das danças afro-brasileiras, acreditamos que a marca da Ciranda é exatamente esse oposto, por apresentar um caráter improvisacional e que as técnicas que a envolve são permeadas pelas técnicas dos corpos que a dançam naquela hora exata em que acontece, portanto, não se limita a um padrão fixo, mas está aberta a novas criações.

Sabemos que em algumas danças da tradição, como por exemplo, o Bumba-meuBoi, o Pastoril, a Chegança, embora exista um sentido para o brincante estar ali e que a 
compreensão do fenômeno seja significativa em sua existência, indo para além do momento da apresentação em si, é possível perceber que há na mostra estética dessas danças um roteiro e uma narrativa construídos em suas músicas e em sua géstica. Acreditamos que na Ciranda essa formalidade não se faz necessária, pois a partir da regra básica que é a formação da roda, o restante torna-se fluido com o desenvolver da dança no corpo dos participantes envolvidos, já que as canções não apresentam teor dramatúrgico a ser seguido ou interpretado.

O corpo na Ciranda está apresentado em forma de dança própria de um povo, dos lugares mais diversos, que concentra no seu cotidiano suas melhores técnicas. Ao falar de técnicas, dialogamos com a concepção de Marcel Mauss (1974) em que o corpo é o resultado de uma construção simbólica e cultural de maneira que toda sociedade se utiliza de formas para marcar o corpo de seus indivíduos. Sob esse aspecto, é importante conhecer como os diferentes povos fazem usos de seus corpos. Na realidade, o fundamento básico é que o homem, sempre e em toda parte, soube fazer uso de seu corpo e com isso desenvolveu suas técnicas e suas representações. Dessa forma, a sociedade "fabrica", em cada lugar e momento histórico, estereótipos e modelos de comportamento que se inscrevem no corpo, ou seja, técnicas corporais, compreendidas pelo autor como "[...] às maneiras pelas quais os homens de sociedade em sociedade, de uma forma tradicional, sabem servir-se de seus corpos" (MAUSS, 1974, p. 211).

Ao dançar a Ciranda, os brincantes trazem à cena suas técnicas sociais e culturais adquiridas pelo trabalho na praia para os nativos, das tarefas aceleradas do público dos grandes centros urbanos, da dona de casa, do estudante que faz da festa na praça, na rua, nos teatros, uma coreografia de pura magia, expressando que a verdadeira forma de ser dançarino é dançando a vida para alcançar um misterioso encanto e um bem viver, e da melhor forma descansar quando Ihe chegar o morrer. Nesse sentido, Merleau-Ponty afirma:

Não é o sujeito epistemológico que efetua a síntese, é o corpo; quando sai de sua dispersão, se ordena, se dirige por todos os meios para um termo único de seu movimento, e quando, pelo fenômeno da sinergia, uma intenção única se concebe nele (MERLEAU-PONTY, 1994, p. 312).

A leitura em Merleau-Ponty sobre o corpo leva-nos a crer que há na Ciranda um corpo sensível, poroso, que dá-se a ver entre a carne do meu corpo, através do olhar, e a carne do mundo; que permite os desdobramentos do meu corpo e das coisas como imbricação no mundo. No bailado, as mãos do brincante revela sua textura de sensações, suas cores. A disposição, a força, a energia empregada, a vivacidade emanada no levantar de braços, tudo é cena do ato festivo; cena esta que, embora sendo por muitos observada, consegue diluir a presença do público, voltando-se a sua própria execução em seus corpos brincantes.

Ao considerarmos o olhar fenomenológico merleau-pontiano, este nos ajuda a pensar em um corpo que não é tratado apenas por comandos que são acionados em suas funções biológicas, de ajustes corretos, mas sim, que podem ser compreendidas por nossa relação com nós mesmos e os atos da experiência pessoal. Por isso, embora a fenomenologia não trate da dança especificamente, podemos apontar a movimentação vista 
nas danças da tradição como uma relação que é tecida pelo corpo vivo que ao lançar-se no mundo, se significa de sentidos, sendo a dança, um modo de ser do corpo.

Por isso, ao presenciar essa dança em diversos lugares vemos que o aprender para tal perpetuação não requer uma aprendizagem formal como observamos em técnicas de danças como Ballet, Tango e outras, mas num mover-se que acontece por significar o feito a uma forma de existir, que acontece para dar sentido à vida, sendo o corpo o instrumento da consolidação da movimentação, pois "[...] um movimento é apreendido quando o corpo compreendeu, quando ele incorporou a seu mundo, e mover as coisas é, visar às coisas através dele" (MERLEAU-PONTY, 1999, p. 65).

Ao dançar, os brincantes reforçam a canção ao acompanhá-las junto à mestra Cirandeira. Os registros descritivos de Evandro Rabelo (1979) constatam fatos que fomos sentindo e refletindo a partir da observação e vivência nas rodas: os passos tradicionais vão sendo reelaborados por seus brincantes, sendo pulverizada de movimentos de outras danças, populares ou não, e assim, em algum instante o brincante tradicional, nativo da beira-mar da praia de Jaguaribe, ao dançar a Ciranda em outros espaços e com outro público que não os de sua localidade, se pergunta: e isso é Ciranda?

Essa pergunta ecoou também em nós ao perceber o quanto a Cirandeira e sua equipe de trabalho observa os movimentos inusitados dos brincantes em algumas apresentações e sente-se surpreendidos e que partindo da referência do seu lugar primeiro, a Praia de Jaguaribe na llha de Itamaracá, parece não se tratar da mesma Ciranda. Constatamos que toda essa atualização de movimentos e géstica ainda vem passando por um processo de transição que se coloca num entre-lugar, daqueles que simbolizam a tradição e daqueles que dançam "do jeito que sabem", com as técnicas do seu próprio corpo, pois se por um lado temos a disseminação da dança da Ciranda, no outro precisamos assumir as consequências dessa expansão.

Dançando, o corpo brincante cirandeiro tece sua escrita. Ele comunica pelos gestos, expressões, músicas, movimentação. Ele expressa o indizível, o cultural, o simbólico, a representação e, sobretudo, a si próprio. Vieira (2012, p. 162) nos auxilia ao falar sobre o corpo brincante das danças da tradição, afirmando que este corpo

[...] se faz poética através das cançonetas, que desperta e reconvoca seus brincantes para melhor brincar e perceber par além das coisas já ditas, já vistas, já percebidas. Corpos que consideram linguagem dos gestos, que convidam a ouvir, a ver, que se deixam falar, que acionam suas capacidades expressivas, encarnadas, corpos que inauguram sentidos, que se movem para significar, para comunicar, para serem lembrados, que se deixam falar, criar, que se direcionam a um educar aberto à transformação, à inovação.

Ao transcender o "já dito", o corpo assume uma poética que pode ser vista e silenciosa ao mesmo tempo, uma vez que diria não ser possível conhecer todas as áreas do corpo por não alcançarmos o silêncio nele impregnado. Nóbrega (2010) reforça essa ideia ao tratar do corpo como sujeito encarnado que está em constante metamorfose e é possuidor de segredos, matéria do irrefletido; por isso, mostra-se ao mesmo tempo que se esconde. 
Nas danças da tradição, o corpo se apresenta como o excesso da fala da experiência de seus participantes, revelando a poesia da sua comunidade, do seu lugar e fazendo-o existir enquanto linguagem, não apenas como matéria. Ele é o que ele diz. Essa linguagem vai se colocando de forma inesgotável por ser renovada a cada nova/antiga dança e movimentação. O corpo de agora não será o mesmo de amanhã, portanto, será vivaz ou não, mais festivo ou menos, e consequentemente a dança que nele se apresenta.

\section{CONSIDERAÇÕES FINAIS}

Nessa circularidade, vemos que o que acontece na roda da Ciranda encontra outros caminhos que não passam por ensaios definidos nem por uma dramaturgia cênica evolutiva. É possível dizer que há, sim, em seus brincantes, um acordo informal e subjetivo ao observarmos que há nos figurinos das mulheres, por exemplo, a presença de saias e vestidos rodados, enfeites no cabelo, chapéus na cabeça dos homens que sugere uma preparação para a participação do fenômeno, mas não se trata de um figurino elaborado especificamente para este fim, com intuito de causar padronização até porque o público da Ciranda de Lia é diverso.

Entrar na roda da Ciranda faz parte de uma escolha que acontece porque, ao ecoar em sua corporeidade, o corpo tratou dela ocupar-se, já que este se atinge e se envolve em torno das coisas que o tocam. Assim, encontrando-se encantado, convencido, o corpo dá-se à poética do mundo em forma de movimentos, que são expressos se dando a ver, sem, no entanto, ter tal finalidade como primeira.

A Ciranda é este lugar de poética, de intersecção de mãos, de vidas, de técnicas, de tradição e de atualidade, compreendido como algo que não é homogêneo e que embora esteja religado ao passado, é ao mesmo tempo atual pois ela acontece no corpo, nele se faz evento e se presentifica. Olhar para a Cirandeira Lia de Itamaracá, é ver história passada e presente imbricadas, e ainda futuro, pois sua vivacidade ainda tem muita coisa pra cantar:

Lia, sou Lia.

Eu sou Lia de Itamaracá

Trago os meus cirandeiros

no passo na dança,

na pancada do mar

Trago os meus cirandeiros

no passo na dança, pela praia

(Cirandando pela Praia - Carlos Zens) 


\section{REFERÊNCIAS}

CASCUDO, Luís da Câmara. Dicionário do Folclore Brasileiro. Ed. 10. São Paulo: Global, 2001.

D’AMORIM, Elvira. ARAÚJO, Dinalva. Do lundu ao samba: pelos caminhos do coco. João Pessoa: Ideia/Arpoador, 2003.

MARTINS, Joel. Um enfoque fenomenológico do currículo: educação como poiésis. São Paulo: Cortez, 1992.

MAUSS, Marcel. As Técnicas Corporais. In: Sociologia e Antropologia. vol. 2. São Paulo: EPU/EDUSP, 1974.

MERLEAU-PONTY, Maurice. Fenomenologia da percepção. São Paulo: Martins Fontes, 1994. O visível e o invisível. São Paulo: Perspectiva, 1999.

NÓBREGA. Terezinha Petrucia da. Uma fenomenologia do corpo. São Paulo: Editora Livraria da Física, 2010.

OTELO, Renata Celina de Morais. Corpos da Ciranda: narrativas poéticas, artístico/estética das Cirandas de Lia de Itamaracá. Dissertação de Mestrado: Programa de Pós- graduação em Artes Cênicas - UFRN, 2016.

SANTOS, Inaicyra Falcão. Corpo e ancestralidade: uma proposta pluricultural de dança-arteeducação. 2 a Edição. São Paulo: Terceira Imagem, 2006.

TELLER. Sonia. História do corpo através da dança da ciranda: Lia de Itamaracá. Dissertação (Mestrado em História), São Paulo, 2009.

VIEIRA. Marcilio de Souza. Pastoril: uma educação celebrada no corpo e no riso. Jundiaí: Paco editorial, 2012. 